\title{
Stochastic Planning - Forecasting Sales and Profits in the Production System
}

\author{
KREMLJAK, Z. \& HOCEVAR, M.
}

Abstract: Forecasting is for the companies of great importance. It is required at a number of levels and it is necessary for planning and operating a future system that will be required to accommodate many forms of uncertainty. The main purpose of forecasting is to provide information to support decision-making and to anticipate changes. Three basic forecasting methods are intuition, extrapolation and prediction. In the paper, we are presenting the forecasting results (six calculation methods were applied) for the volume of sales and profit, based on the collected data for past years in a small company.

Key words: stochastic, sales, profit, planning, forecasting
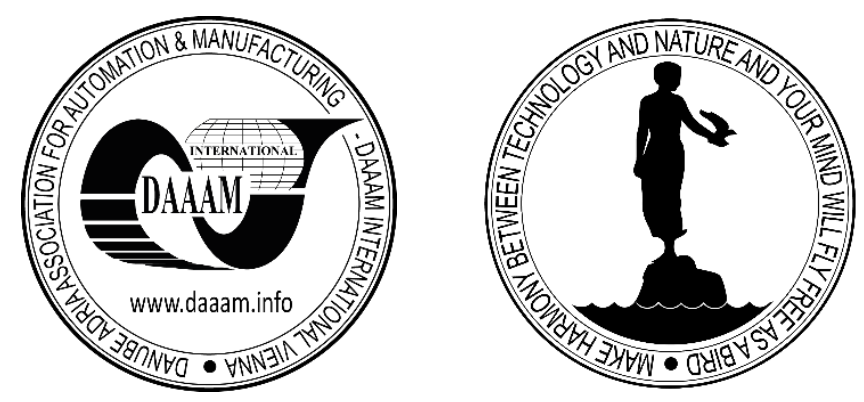

Authors' data: Asst. Prof. Dr. Sc. Kremljak, Z[vonko]*; Full Prof. Dr. Sc. Hocevar, M[arko]**, *Telekom Slovenije, d. d., Cigaletova 15, SI - 1000 Ljubljana, Slovenia, EU, **University of Ljubljana, Faculty of Economics, Academic Unit for Accounting and Auditing, Kardeljeva ploscad 17, SI - 1000 Ljubljana, Slovenia, EU, zvonko.kremljak@s5.net, marko.hocevar@ef.uni-lj.si

This Publication has to be referred as: Kremljak, Z[vonko] \& Hocevar, M[arko] (2016). Stochastic Planning - Forecasting Sales and Profits in the Production System, Chapter 03 in DAAAM International Scientific Book 2016, pp.025-038, B. Katalinic (Ed.), Published by DAAAM International, ISBN 978-3-902734-09-9, ISSN 17269687, Vienna, Austria

DOI: $10.2507 /$ daaam.scibook.2016.03 
Kremljak, Z. \& Hocevar, M.: Stochastic Planning - Forecasting Sales and Profits in...

\section{Introduction}

The forecast of the production systems just as the environmental forecast on the level of long term, medium term and short term planning techniques is of great importance in the modern business operational plans as well (Herrmann, 2014). Business processes are persistent, since we assume on developments in the future from past events through current events. Since many processes have stochastic nature, the prediction of future events subordinates to the stochastic laws, which obviously are not entirely reliable (therefore, we refer the forecasting as stochastic planning) (Berry, 2016).

In the production environment of a company, the forecasting is present at several places (Blackburn et al., 2015). Thus, in the process of production forecasting, the stochastic methods are used for:

- Demand and sales forecasting, i.e. for creation of sales plans at the level of planning of the production program;

- Forecasting the duration of the production cycle for various products;

- Forecasting the material consumption (or components) at the level of planning of the material requirements and automatic completion of stocks as well;

- Forecasting the poor quality (scrap);

- Forecasting the maintenance activities within the company (maintenance costs, time spent on maintenance, ...)

- Forecasting the availability of production capacities (announcement of job loss due to damage of assets, absence of workers).

The forecast may be purely descriptive (numerical description of the forecasted events) or quantitative (numerical value of the forecasted events). While planning the production process we shall avoid the descriptive forecasts, as they can often be very ambiguous to interpret and can lead to wrong decisions (Bajric et al., 2015).

\section{Forecasting methods}

The basic division of forecasting methods takes into account the planning horizon or planning period and learns about (Ljubic, 2006):

- Technological forecasting, which extends very far (several decades) into the future,

- Long term forecasting for a period of 3 to 10 years ahead,

- Short term forecasting with a forecasting period of 1 to 2 years or even less.

Short term forecasting methods can be divided into two groups. Qualitative methods, which are informal and based primarily on human experience and subjective assessments; a typical qualitative method is the experiential evaluation, which we take into consideration whenever we have no exact data available about the occurrence that we are about to forecast, but only the experience of similar occurrences (Ho, 2013). On the other hand, the quantitative methods are formal procedures, which presuppose the already mentioned persistence of the process and they use data, which refers to some occurrence from the past and mathematical methods in order to forecast the future occurrences; which could be further divided into: 
- Extrapolation methods,

- Correlation methods (Fig. 1).

Extrapolation methods assume that the movement of a certain occurrence is primarily a time-function and they identify it's value easily by using statistical analysis on the value in the past and extrapolate it into the future.

On the other hand, the correlation methods argue that the movement of certain occurrence correlates with a number of external factors and that the time-factor is one of them. By application of appropriate statistical methods, it is possible to identify and quantify the correlation. On the assumption that the correlation lasts for long time, we can forecast the value of the observed occurrence in terms of all the possible values of factors, which correlate. This group for example includes the regression analysis. Both correlation and extrapolation methods require statistical data on how and under what conditions the observed occurrence behaved in the past (Slack et al., 2010).

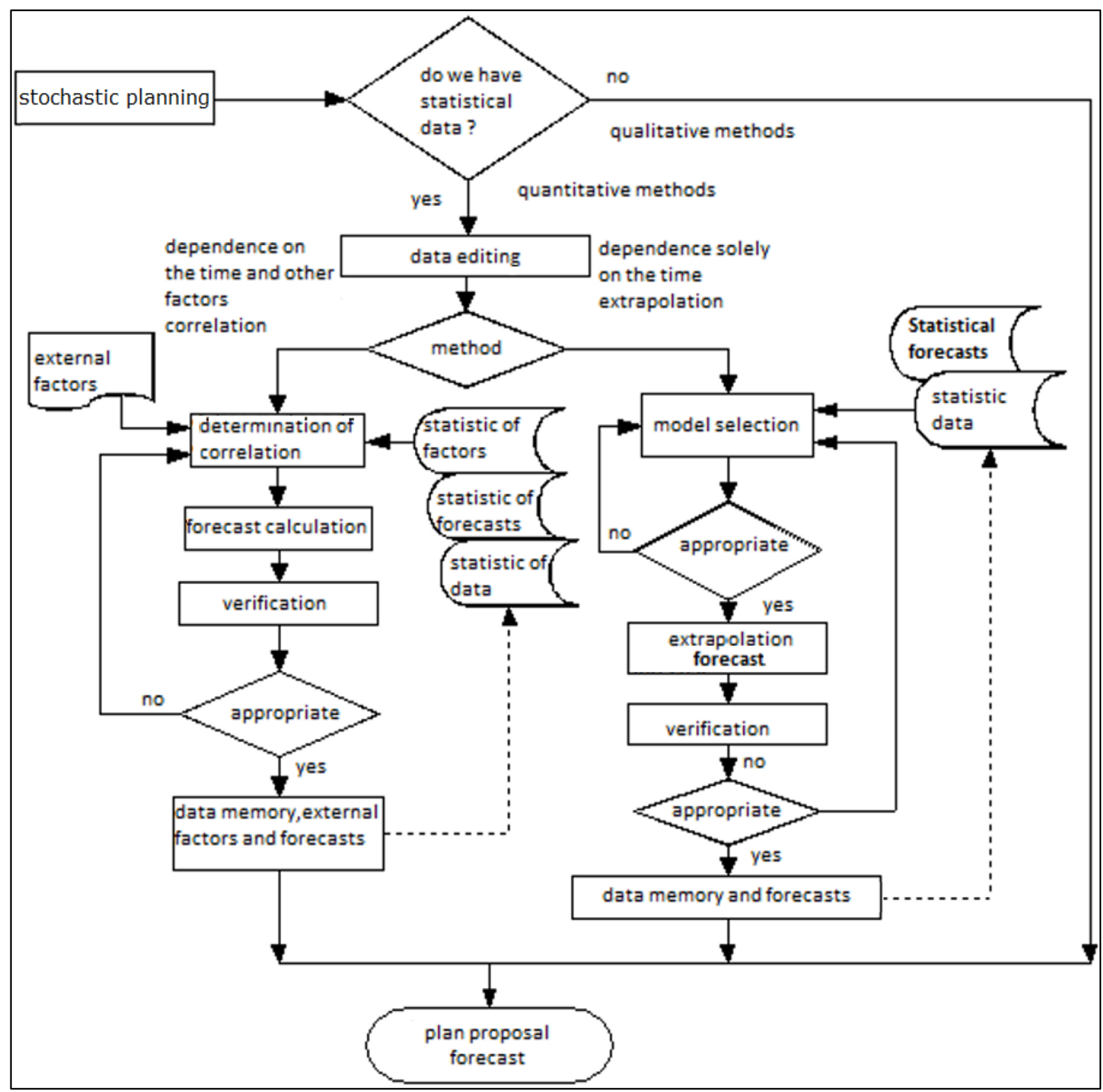

Fig. 1. Principled course of forecast - stochastic forecasting 
Kremljak, Z. \& Hocevar, M.: Stochastic Planning - Forecasting Sales and Profits in...

\subsection{Measurement of the forecasting accuracy}

The measurement of forecasting (planning) accuracy indicates how much the actually achieved values differ from those anticipated, planned values.

An important characteristic of each prediction is its reliability. Highly appropriate criteria for the reliability of the forecast is the average absolute forecast error and the average (median) absolute deviation (MAD - Mean Absolute Deviation), which is calculated from the absolute value of the difference between the actual value and the arithmetic mean of the predicted values of events (Michis, 2015).

$$
M A D=\frac{\sum_{i=1}^{n}\left|\left(R_{i}-F_{i}\right)\right|}{n}
$$

wherein:

$M A D$ - mean absolute deviation of the forecast,

$R_{i} \quad$ - actual value of the event,

$F_{i} \quad$ - forecasted value of the event,

I - index of the event, $i=1 \ldots n$,

$n-$ number of observed events.

$M A D$ represents the size of the average forecast error regardless of whether it is positive (too small) or negative (excess return). We shall at no case confuse $M A D$ with the variance $\sigma^{2}$ or the standard deviation $\sigma$.

On the assumption that there is a sufficient number of forecasts and actual values and that the distribution of the forecast values and actual values is subordinated to the law of normal distribution, it is simplistic to summarize that $\sigma \cong 1,25 \cdot M A D$ or $M A D \cong 0,8 \cdot \sigma$.

\section{Extrapolation forecasting methods}

The forecast of the occurrence's value $Y$ is carried out simply by assuming its persistence - we increase the value of the independent variable $x$ over the value of the last statistical data and we calculate the corresponding value of $Y$, as shown in Fig. 2.

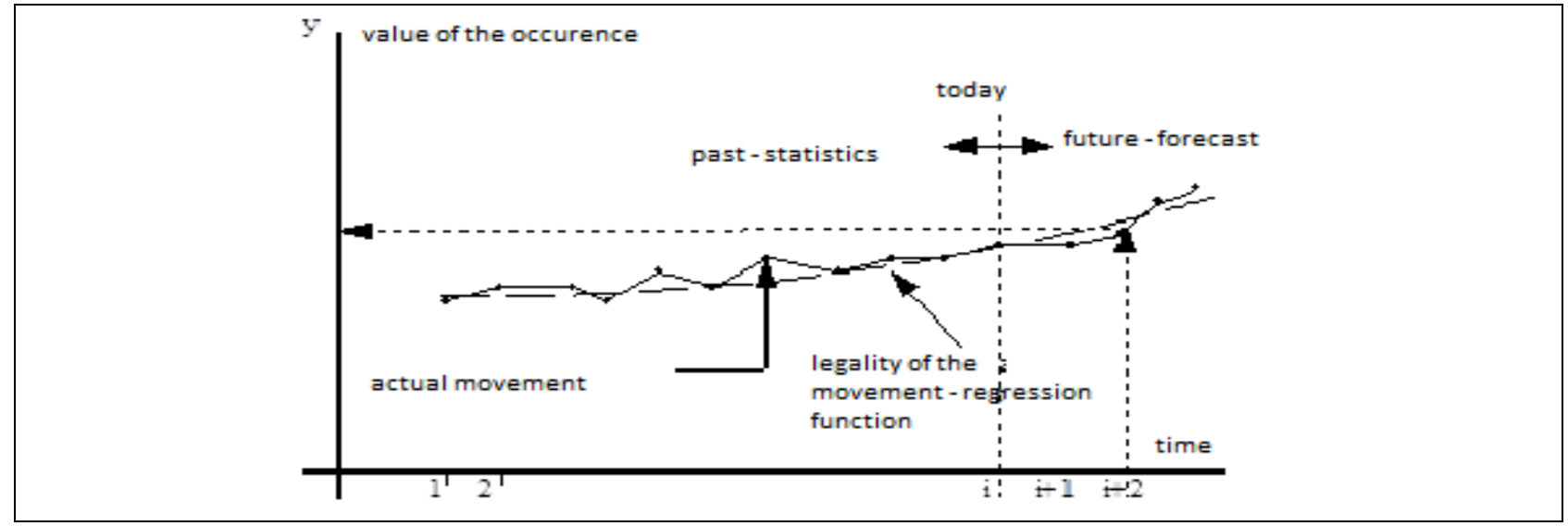

Fig. 2. Use of the legality movement of the occurrence in timetable in order to forecast the value of the occurrence in the future 


\subsection{Linear regression of the first tier}

In case of linear regression, we assume that the function, which best fits the observed occurrence is a straight line with the following equation:

$$
y=a+b \cdot x
$$

Regression constant $a$ represents basic value of the occurrence at time 0 , while regression coefficient $b$ is in the time series trend - increment or decrease in value occurs within one period.

Simplest way to calculate the value of the regression constant, the regression coefficient, the coefficient of determination and the correlation index as well is by applying the method of least squares from the system of equations:

$$
\begin{aligned}
& a \cdot n+b \cdot \sum x=\sum y \\
& a \cdot \sum x+b \cdot \sum\left(x^{2}\right)=\sum x \cdot y \\
& a=\frac{\sum y-b \cdot \sum x}{n} \\
& b=\frac{n \cdot \sum x \cdot y-\sum x \cdot \sum y}{n \sum\left(x^{2}\right)-\left(\sum x\right)^{2}} \\
& r^{2}=\frac{\left[\sum x \cdot y-\frac{1}{n} \cdot \sum x \cdot \sum y\right]^{2}}{\left[\sum\left(x^{2}\right)-\frac{1}{n}\left(\sum x\right)^{2}\right] \cdot\left[\sum\left(y^{2}\right)-\frac{1}{n} \cdot\left(\sum y\right)^{2}\right]}
\end{aligned}
$$

$a$ - regression constant,

$b-$ regression coefficient,

$x$ - independent variable - time, counted from 1 onwards, $x=1 \ldots n$,

$y$ - dependent variable-observed occurrence,

$n$ - number of periods, for which we have statistical data,

$r^{2}$ - coefficient of determination (whether the regression function is really close to the straight line),

$r$ - correlation index (how strong is the connection between $x$ and $y$ ) $r=\sqrt{r^{2}}$

The value of the coefficient of determination lies between 0 and 1 ; we consider that the regression function is close enough to the straight line if $r^{2}>0.75$.

\subsection{Nonlinear regression of the first tier}

The straight line as regression function does not always fits best the observed occurrence. It happens that a curve meant to illustrate the legality of the occurrence is more appropriate - that is how we get to the nonlinear regression of the first tier. Curves 
Kremljak, Z. \& Hocevar, M.: Stochastic Planning - Forecasting Sales and Profits in... of the first tier that we encounter in the process are curves of exponential functions and various forms of curves from logarithmic functions.

In case of nonlinear regression of the first tier, we can calculate the value of the regression constant and the value of the regression coefficient by applying the method of least squares from the system of normal equations.

Most frequently, we encounter four curves of the first tier.

Exponential function:

$$
y=a \cdot b^{x}
$$

or when we choose to apply $\log$ arithm: $\log y=\log a+x \cdot \log b$

$$
\begin{array}{lc}
\log a \cdot n+\log b \cdot \sum x=\sum \log y & \log b=\frac{n \cdot \sum x \cdot \log y-\sum x \cdot \sum \log y}{n \cdot \sum\left(x^{2}\right)-\left(\sum x\right)^{2}} \\
\log a \cdot \sum x+\log b \cdot \sum\left(x^{2}\right)=\sum x \cdot \log y & \log a=\frac{\sum \log y-\log b \cdot \sum x}{n}
\end{array}
$$

First type the logarithmic functions:

$$
\begin{aligned}
& y=a+b \cdot \log x \\
& a \cdot n+b \cdot \sum \log x=\sum y b=\frac{n \cdot \sum y \cdot \log x-\sum \log x \cdot \sum y}{n \cdot \sum(\log x)^{2}-\left(\sum \log x\right)^{2}} \\
& a \cdot \sum \log x+b \cdot \sum(\log x)^{2}=\sum y \cdot \log x a=\frac{\sum y-b \cdot \sum \log x}{n}
\end{aligned}
$$

Second type the logarithmic functions:

$\log y=a+b \cdot x$

$$
\begin{aligned}
& a \cdot n+b \cdot \sum x=\sum \log y \quad a \cdot \sum x+b \cdot \sum\left(x^{2}\right)=\sum x \cdot \log y \\
& b=\frac{n \cdot \sum x \cdot \log y-\sum x \cdot \sum \log y}{n \cdot \sum\left(x^{2}\right)-\left(\sum x\right)^{2}} \quad a=\frac{\sum \log y-b \cdot \sum x}{n}
\end{aligned}
$$

Third type the logarithmic functions:

$\log y=a+b \cdot \log x$

$$
\begin{aligned}
& a \cdot n+b \cdot \sum \log x=\sum \log y b=\frac{n \cdot \sum \log x \cdot \log y-\sum \log x \cdot \sum \log y}{n \cdot \sum(\log x)^{2}-\left(\sum \log x\right)^{2}} \\
& a \cdot \sum \log x+b \cdot \sum(\log x)^{2}=\sum \log x \cdot \log y a=\frac{\sum \log y-b \cdot \sum \log x}{n}
\end{aligned}
$$




\subsection{Method of weighted mean value}

Under this method, we can assign different weights on different aged data regarding an occurrence in the past in a way that the proportions of different aged data differ in the forecast. In such case, we are talking about weighted arithmetic mean. In the expression for calculation we do not use precisely all the statistics, but the data for some periods and it may be written in the following form:

$$
F_{i+1}=\bar{R}^{\prime}=\frac{1}{m} \cdot \sum_{i=n-m+1}^{n} R_{i}=\sum_{i=n-m+1}^{n} \frac{1}{m} \cdot R_{i}=\sum_{i=n-m+1}^{n} q_{j} \cdot R_{i}
$$

$q_{j}-$ ponder (weight) of particular data in the time series, $j=1 \ldots m$.

Values of the individual data lies between 0 and 1, they are in principle less than 1 , the sum of all weights must be equal to 1 . In case that we give more weight to the older data (data from the initial time series moving average), we try to calm the forecast of the occurrence and vice versa in case when we give more weight to the newer data (data from the end of the time series moving average), as the forecast will more likely follow the actual movement of the occurrence (Lin \& Chou, 2013).

\section{Example of calculation}

We collected data on the volume of sales and profit in a smaller company (after the reorganization) for the period from 2013 to 2015 (in Tables 1 and 2 and in Figs. 3 and 4). The main limitation of the research is in the fact that we have real data for only three years period. The second limitation is within our selection of forecasting methods.

\begin{tabular}{|c|c|c|}
\hline$i$ & Year & Sales \\
\hline 1 & 2013 & 22.957 .000 EUR \\
\hline 2 & 2014 & 24.105 .000 EUR \\
\hline 3 & 2015 & 25.793 .000 EUR \\
\hline
\end{tabular}

Tab. 1. Volume of sales.

\begin{tabular}{|c|c|c|}
\hline$i$ & Year & Profit \\
\hline 1 & 2013 & 490.811 EUR \\
\hline 2 & 2014 & 699.568 EUR \\
\hline 3 & 2015 & 949.421 EUR \\
\hline
\end{tabular}

Tab. 2. Profit in the period 2013-2015.

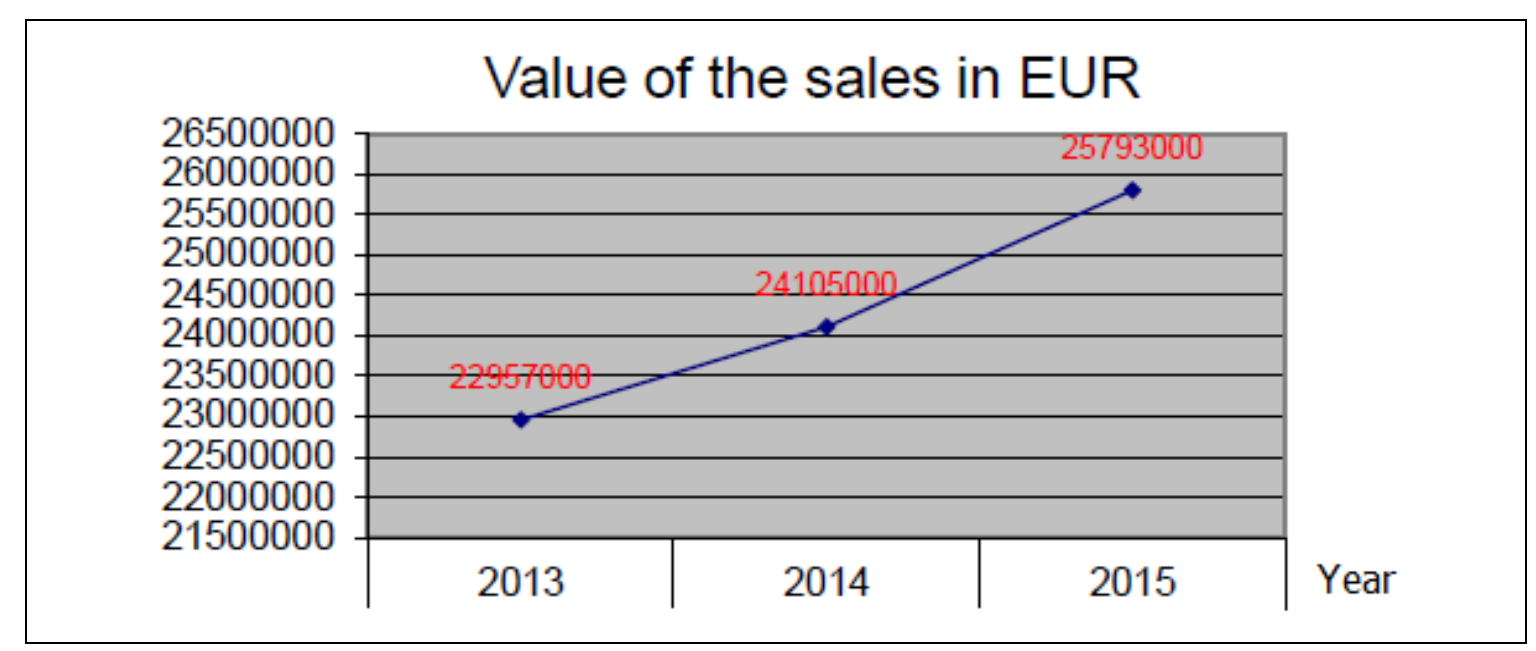

Fig. 3. Changes in the value of the sales in EUR 
Kremljak, Z. \& Hocevar, M.: Stochastic Planning - Forecasting Sales and Profits in...

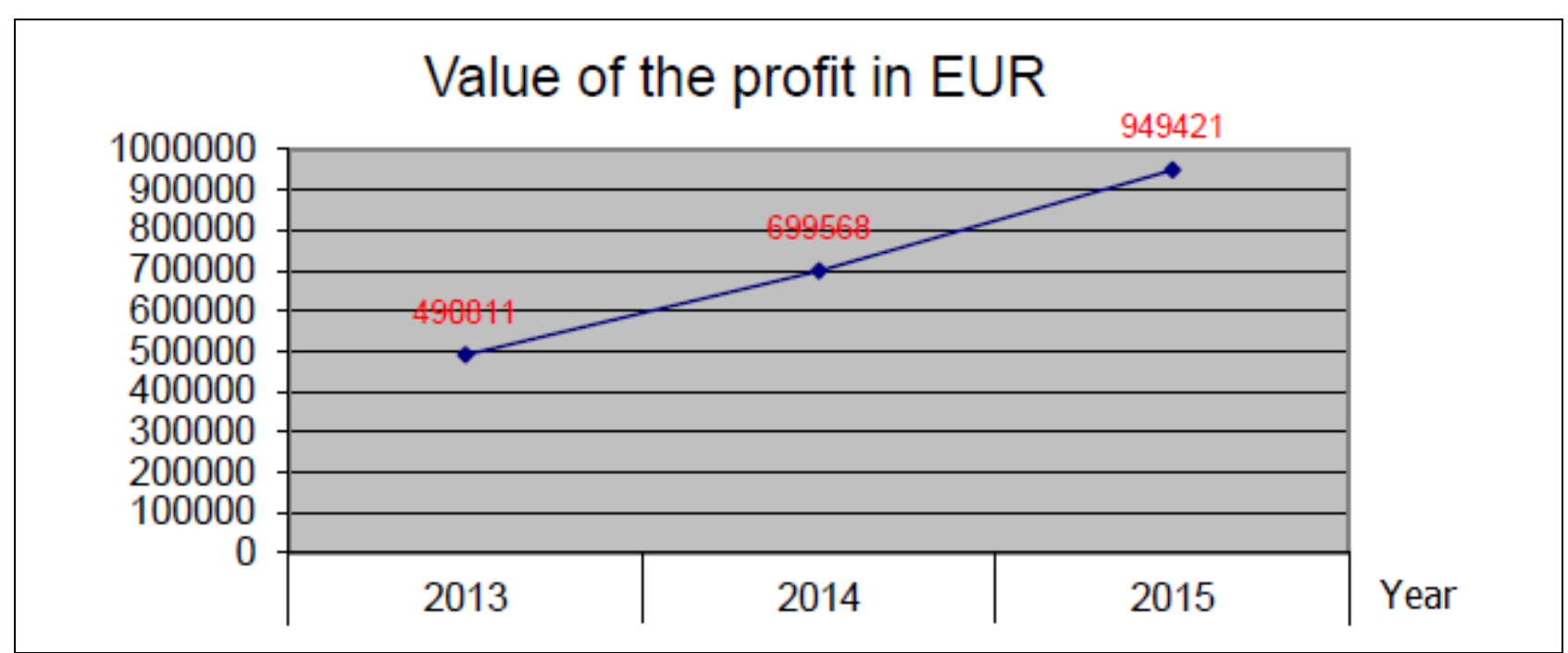

Fig. 4. Changes in the value of the profit in EUR

\subsection{Forecast for the next two years by applying the linear regression of the first tier}

First, we arrange the data in tabular form, we scale the value $R_{i}$ (actual value for sales) by a factor of $10^{6}$ and the value $R_{i}$ (actual value for profit) by a factor of $10^{5}$ and we enter the both values in the column $Y$. The data is collected in Tables 3 and 4.

\begin{tabular}{|c|c|c|}
\hline$i$ & $R_{i}$ & $y$ \\
\hline 1 & 22.957 .000 & 23,0 \\
\hline 2 & 24.105 .000 & 24,1 \\
\hline 3 & 25.793 .000 & 25,8 \\
\hline
\end{tabular}

Tab. 3. Actual and scaled values of sales.

\begin{tabular}{|c|c|c|}
\hline$i$ & $R_{i}$ & $y$ \\
\hline 1 & 490.811 & 4,9 \\
\hline 2 & 699.568 & 7,0 \\
\hline 3 & 949.421 & 9,5 \\
\hline
\end{tabular}

Tab. 4. Actual and scaled values of profit.

a) Sales

Regression function has the following form:

$y=a+b \cdot x=21.43+1.4 x$

Coefficient of determination:

$$
\begin{aligned}
& r^{2}=\frac{\left(148,2-\frac{1}{3} * 6 * 72,7\right)^{2}}{\left(14-\frac{1}{3} * 36\right)\left(1778,28-\frac{1}{3}(72,7)^{2}\right)}=0,436 \\
& r=0,66
\end{aligned}
$$

Forecast for the years 2016 and 2017 (Table 5):

$x=4 ; y_{4}=21,43+1,4 \cdot 4=27,03$

$x=5 ; y_{5}=21,43+1,4 \cdot 5=28,43$ 


\begin{tabular}{|c|c|c|}
\hline Year & $R_{i}$ & $F_{i}$ \\
\hline 2013 & 22.957 .000 & 22.830 .000 \\
\hline 2014 & 24.105 .000 & 24.230 .000 \\
\hline 2015 & 25.793 .000 & 25.630 .000 \\
\hline 2016 & & 27.030 .000 \\
\hline 2017 & & 28.430 .000 \\
\hline
\end{tabular}

Tab. 5. Forecast of sales for the year 2016 and 2017.

b) Profit

Regression function has the following form:

$y=a+b \cdot x=2,53+2,29 x$

Coefficient of determination:

$r^{2}=\frac{\left(47,35-\frac{1}{3} * 6 * 21,38\right)^{2}}{\left(14-\frac{1}{3} * 36\right)\left(475,10-\frac{1}{3}(21,38)^{2}\right)}=0,0344$

$r=0,185$

Forecast for the years 2016 and 2017 (Table 6):

$x=4 ; y_{4}=2,53+2,29 \cdot 4=11,69$

$x=5 ; y_{5}=2,53+2,29 \cdot 5=13,98$

\begin{tabular}{|c|c|c|}
\hline Year & $R_{i}$ & $F_{i}$ \\
\hline 2013 & 490.811 & 482.000 \\
\hline 2014 & 699.568 & 711.000 \\
\hline 2015 & 949.421 & 940.000 \\
\hline 2016 & & 1.169 .000 \\
\hline 2017 & & 1.398 .000 \\
\hline
\end{tabular}

Tab. 6. Forecast of profit for the years 2016 and 2017.

4.2 Forecasting by application of the nonlinear regression of the first tier

We apply the same starting and scaling information for $R_{i}$ or $y$.

Exponential function

a) Sales

Regression function has the following form:

$y=a \cdot b^{x}=21,55 \cdot 1,059^{x}$

Forecast of the sales for the years 2016 and 2017 is presented in Table 7.

\begin{tabular}{|c|c|c|}
\hline Year & $R_{i}$ & $F_{i}$ \\
\hline 2013 & 22.957 .000 & 22.609 .000 \\
\hline 2014 & 24.105 .000 & 24.168 .000 \\
\hline 2015 & 25.793 .000 & 25.594 .000 \\
\hline 2016 & & 27.103 .000 \\
\hline 2017 & & 28.703 .000 \\
\hline
\end{tabular}

Tab. 7. Forecasted values of sales (exponential function) for the years 2015 and 2016. 
Kremljak, Z. \& Hocevar, M.: Stochastic Planning - Forecasting Sales and Profits in...

b) Profit

Regression function has the following form:

$y=a \cdot b^{x}=4,280 \cdot 1,267^{x}$

Forecast for the next two years is presented in Table 8.

\begin{tabular}{|c|c|c|}
\hline Year & $R_{i}$ & $F_{i}$ \\
\hline 2013 & 490.811 & 542.300 \\
\hline 2014 & 699.568 & 687.100 \\
\hline 2015 & 949.421 & 870.500 \\
\hline 2016 & & 1.103 .000 \\
\hline 2017 & & 1.397 .000 \\
\hline
\end{tabular}

Tab. 8. Forecasted values of profit (exponential function) for the years 2015 and 2016.

Logarithmic function - the first form

a) Sales

Regression function has the following form:

$y=a+b \cdot \log x=24,14+0,331 \cdot \log x$

Forecast for the next two years is presented in Table 9.

\begin{tabular}{|c|c|c|}
\hline Year & $R_{i}$ & $F_{i}$ \\
\hline 2013 & 22.957 .000 & 24.140 .000 \\
\hline 2014 & 24.105 .000 & 24.240 .000 \\
\hline 2015 & 25.793 .000 & 24.300 .000 \\
\hline 2016 & & 24.340 .000 \\
\hline 2017 & & 24.370 .000 \\
\hline
\end{tabular}

Tab. 9. Forecasted values of sales by use of logarithmic function - first form.

b) Profit

Regression function has the following form:

$\log y=a+b \cdot x=1,333+0,025 \cdot x$

Forecast for the next two years is presented in Table 10.

\begin{tabular}{|c|c|c|}
\hline Year & $\mathrm{R}_{\mathrm{i}}$ & $\mathrm{F}_{\mathrm{i}}$ \\
\hline 2013 & 490.811 & 699.000 \\
\hline 2014 & 699.568 & 714.000 \\
\hline 2015 & 949.421 & 723.000 \\
\hline 2016 & & 730.000 \\
\hline 2017 & & 735.000 \\
\hline
\end{tabular}

Tab. 10. Forecasted values of profit by use of logarithmic function - first form.

Logarithmic function - second form

a) Sales

Regression function has the following form:

$\log y=a+b \cdot x=1,333+0,025 \cdot x$ 
Forecast for the next two years is presented in Table 11.

\begin{tabular}{|c|c|c|}
\hline Year & $R_{i}$ & $F_{i}$ \\
\hline 2013 & 22.957 .000 & 22.800 .000 \\
\hline 2014 & 24.105 .000 & 24.150 .000 \\
\hline 2015 & 25.793 .000 & 25.590 .000 \\
\hline 2016 & & 27.100 .000 \\
\hline 2017 & & 28.710 .000 \\
\hline
\end{tabular}

Tab. 11. Forecasted values of sales by use of logarithmic function - second form.

b) Profit

Regression function has the following form:

$\log y=a+b \cdot x=0,631+0,103 \cdot x$

Forecast for the next two years is presented in Table 12.

\begin{tabular}{|c|c|c|}
\hline Year & $R_{i}$ & $F_{i}$ \\
\hline 2013 & 490.811 & 542.000 \\
\hline 2014 & 699.568 & 687.000 \\
\hline 2015 & 949.421 & 870.000 \\
\hline 2016 & & 1.104 .000 \\
\hline 2017 & & 1.400 .000 \\
\hline
\end{tabular}

Tab. 12. Forecasted values of profit by use of logarithmic function - second form.

Logarithmic function - third form

a) Sales

Regression function has the following form:

$\log y=a+b \cdot \log x=1,356+0,102 \cdot \log x$

Forecast for the next two years is presented in Table 13.

\begin{tabular}{|c|c|c|}
\hline Year & $R_{i}$ & $F_{i}$ \\
\hline 2013 & 22.957 .000 & 22.700 .000 \\
\hline 2014 & 24.105 .000 & 24.360 .000 \\
\hline 2015 & 25.793 .000 & 25.390 .000 \\
\hline 2016 & & 26.150 .000 \\
\hline 2017 & & 26.750 .000 \\
\hline
\end{tabular}

Tab. 13. Forecasted values of sales by use of logarithmic function - third form.

b) Profit

Regression function has the following form:

$\log y=a+b \cdot \log x=0,769+0,034 \cdot \log x$

Forecast for the next two years is presented in Table 14 . 
Kremljak, Z. \& Hocevar, M.: Stochastic Planning - Forecasting Sales and Profits in...

\begin{tabular}{|c|c|c|}
\hline Year & $R_{i}$ & $F_{i}$ \\
\hline 2013 & 490.811 & 587.000 \\
\hline 2014 & 699.568 & 601.000 \\
\hline 2015 & 949.421 & 609.000 \\
\hline 2016 & & 615.000 \\
\hline 2017 & & 621.000 \\
\hline
\end{tabular}

Tab. 14. Forecasted values of profit by use of logarithmic function - third form.

\subsection{Forecasting by use of the method of weighted mean value}

We will use two kinds of weights, namely $q_{j(1)}$, which will give more weight to the older data and $q_{j(2)}$, which will give greater weight to the newer data, whereas the forecast should be followed by the actual movement (Table 15).

\begin{tabular}{|c|c|c|}
\hline$j$ & $q_{j(1)}$ & $q_{j(2)}$ \\
\hline 1 & 0,56 & 0,11 \\
\hline 2 & 0,33 & 0,33 \\
\hline 3 & 0,11 & 0,56 \\
\hline$\Sigma q_{j}$ & 1 & 1 \\
\hline
\end{tabular}

Tab. 15. Table of weights.

a) Sales

Example of calculation of the forecast for the year 2016 (data has being scaled by factor of $10^{6}$ ):

$$
\begin{aligned}
& F_{4(1)}=q_{j} \cdot R_{i}=23,0 \cdot 0,56+24,1 \cdot 0,33+25,8 \cdot 0,11=23,67 \\
& F_{4(2)}=q_{j} \cdot R_{i}=23,0 \cdot 0,11+24,1 \cdot 0,33+25,8 \cdot 0,56=24,93
\end{aligned}
$$

\begin{tabular}{|c|c|c|c|}
\hline$i$ & $R_{i}$ & $F_{i q(1)}$ & $F_{i q(2)}$ \\
\hline 1 & 23,0 & & \\
\hline 3 & 24,1 & & \\
\hline 4 & 25,8 & & 24,93 \\
\hline
\end{tabular}

Tab. 16. Forecasted values of sales by the use of the method of weighted mean value.

b) Profit

Example of calculation of the forecast for the year 2016 (data has being scaled by factor of $10^{5}$ ):

$$
\begin{aligned}
& F_{4(1)}=q_{j} \cdot R_{i}=4,9 \cdot 0,56+7,0 \cdot 0,33+9,5 \cdot 0,11=6,1 \\
& F_{4(1)}=q_{j} \cdot R_{i}=4,9 \cdot 0,11+7,0 \cdot 0,33+9,5 \cdot 0,56=8,2
\end{aligned}
$$

\begin{tabular}{|c|c|c|c|}
\hline$i$ & $R_{i}$ & $\mathrm{~F}_{\mathrm{iq}(1)}$ & $\mathrm{F}_{\mathrm{iq}(2)}$ \\
\hline 1 & 4,9 & & \\
\hline 3 & 7,0 & & \\
\hline 4 & 9,5 & & 8,2 \\
\hline
\end{tabular}

Tab. 17. Forecasted values of profit by the use of the method of weighted mean value. 
We note large deviations of the calculated values from the movement of the actual value, which indicates weaknesses of this method. This method is appropriate in case of movement of the values (ups and downs) - when the result is only increasing the weighted mean value will be always set up too low.

\section{Comparison of the forecast results}

\subsection{Sales}

\begin{tabular}{|c|c|c|c|c|c|c|c|}
\hline Year & $\begin{array}{c}R_{i}- \\
\text { actual } \\
\text { value }\end{array}$ & $\begin{array}{c}F_{i}- \\
\text { exponential } \\
\text { function }\end{array}$ & $\begin{array}{c}\text { Logarithmic } \\
\text { function }- \\
\text { first form }\end{array}$ & $\begin{array}{c}F_{i}- \\
\text { Logarithmic } \\
\text { function - } \\
\text { second form }\end{array}$ & $\begin{array}{c}F_{i}- \\
\text { Logarithmic } \\
\text { function - } \\
\text { third form }\end{array}$ & $\begin{array}{c}F_{i q(1)-} \\
\text { weighted } \\
\text { mean value }\end{array}$ & $\begin{array}{c}F_{i q(2)-} \\
\text { weighted } \\
\text { mean value }\end{array}$ \\
\hline 2013 & 23,0 & 22,6 & 24,1 & 22,8 & 22,7 & & \\
\hline 2014 & 24,1 & 24,2 & 24,2 & 24,2 & 24,4 & & \\
\hline 2015 & 25,8 & 25,6 & 24,3 & 25,6 & 25,4 & & 24,9 \\
\hline 2016 & & 27,1 & 24,3 & 27,1 & 26,2 & 23,7 & \\
\hline 2017 & & 28,7 & 24,4 & 28,7 & 26,8 & & \\
\hline
\end{tabular}

Tab. 18. Comparison of the forecast results for sales for each method of forecast.

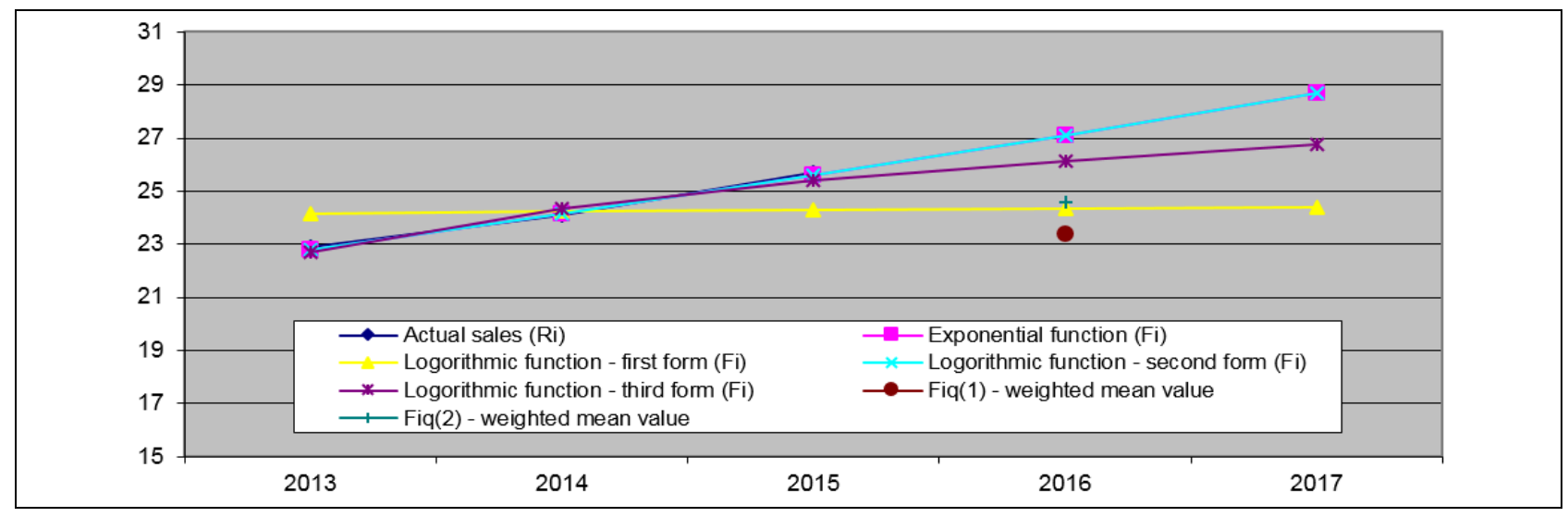

Fig. 5. Comparison of the actual and the forecasted values of sales for used methods

\subsection{Profit}

\begin{tabular}{|c|c|c|c|c|c|c|c|}
\hline Year & $\begin{array}{c}R_{i}- \\
\text { actual } \\
\text { value }\end{array}$ & $\begin{array}{c}F_{i}- \\
\text { exponential } \\
\text { function }\end{array}$ & $\begin{array}{c}F_{i}- \\
\text { Logarithmic } \\
\text { function }- \\
\text { first form }\end{array}$ & $\begin{array}{c}F_{i}- \\
\text { Logarithmic } \\
\text { function - } \\
\text { second form }\end{array}$ & $\begin{array}{c}F_{i}- \\
\text { Logarithmic } \\
\text { function - third } \\
\text { form }\end{array}$ & $\begin{array}{c}F_{i q(1)-} \\
\text { weighted } \\
\text { mean value }\end{array}$ & $\begin{array}{c}F_{i q(2)-} \\
\text { weighted } \\
\text { mean value }\end{array}$ \\
\hline 2013 & 4,9 & 5,4 & 7,0 & 5,4 & 5,9 & & \\
\hline 2014 & 7,0 & 6,9 & 7,1 & 6,9 & 6,0 & & \\
\hline 2015 & 9,5 & 8,7 & 7,2 & 8,7 & 6,1 & & 8,2 \\
\hline 2016 & & 11,0 & 7,3 & 11,0 & 6,2 & 6,1 & \\
\hline 2017 & & 14,0 & 7,4 & 14,0 & 6,2 & & \\
\hline
\end{tabular}

Tab. 19. Comparison of the forecast results for profit for each method of forecast.

As we see from the existing diagrams obtained owing to the statistical forecasting methods (in Figs. 5 and 6), the forecasted sales and profits of the new system are growing, while the economic trends on the market and the recession as well (which are periodically repeating processes) are not taken into account. 
Kremljak, Z. \& Hocevar, M.: Stochastic Planning - Forecasting Sales and Profits in...

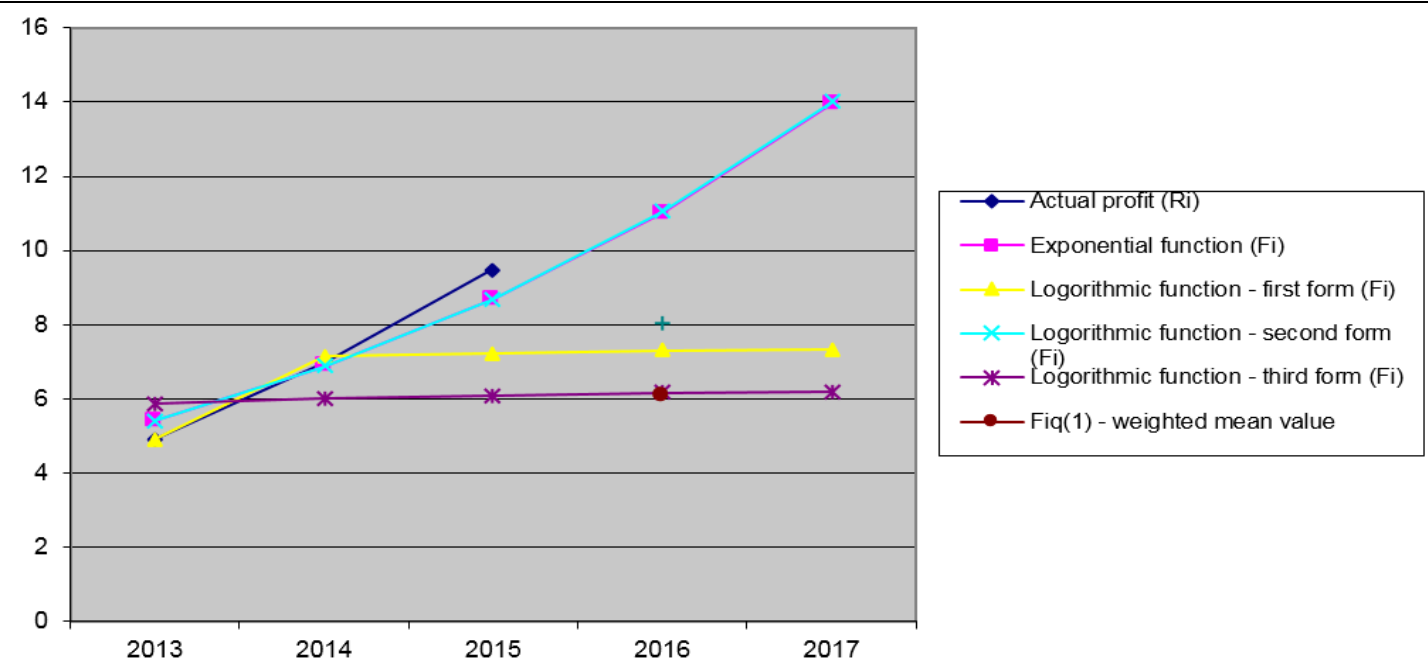

Fig. 6. Comparison of the actual and the forecasted values of profit for used methods

\section{Conclusion}

Sales and profits forecasts are essential parts of all businesses. Since the recession occurs every 5-6 years in the business field of manufacturing products, the results are satisfactory at reasonably stable external factors affecting the new, reorganized system. The main contribution can be seen in a comparison of different forecasting methods, used on the same data sample to enable the selection of the appropriate method.

Future research plans include the introduction of predictive analytics.

\section{References}

Bajric, H.; Kadric, E. \& Pasic, M. (2015). A comparison of Same Slope Seasonality and Holt-Winters smoothing forecasting models, Proceedings of the $26^{\text {th }}$ DAAAM International Symposium, Katalinic, B. (Ed.), pp. 62-68, ISBN 978-3-902734-06-8, Zadar, October 2016, DAAAM Int. Vienna

Berry, T. (2016). Creating a sales forecast. Entrepreneur, available from http://www.entrepreneur.com/article/77674, accessed on 02-03-2016

Blackburn, R.; Lurz, K.; Priese, B.; Goeb, R. \& Darkow, I. L. (2015). A predictive analytics approach for demand forecasting in the process industry. International Transactions in Operational Research, Vol. 22, No. 3, 407-428, ISSN 1475-3995 Herrmann, F. (2014). Principles of business forecasting. Interfaces, Vol. 44, No. 2 , 244-245, ISSN 0092-2102

Ho, P. H. K. (2013). Forecasting tender price index under incomplete information. Journal of the Operational Research Society, Vol. 64, No. 8, 1248-1257

Lin, C.-T. \& Chou L.-D. (2013). A novel economy reflecting short-term load forecasting approach. Energy Conversion and Management, Vol. 65, 331-342

Ljubic, T. (2006). Operations Management (in Slovenian). Moderna organizacija, Kranj Michis, A. A. (2015). A wavelet smoothing method to improve conditional sales forecasting. Journal of the Operational Research Society, Vol. 66, No. 5, 832-844 Slack, N.; Chambers, S. \& Johnston, R. (2010). Operations Management. Financial Times / Prentice Hall, ISBN 978-0-273-73046-0, Harlow 